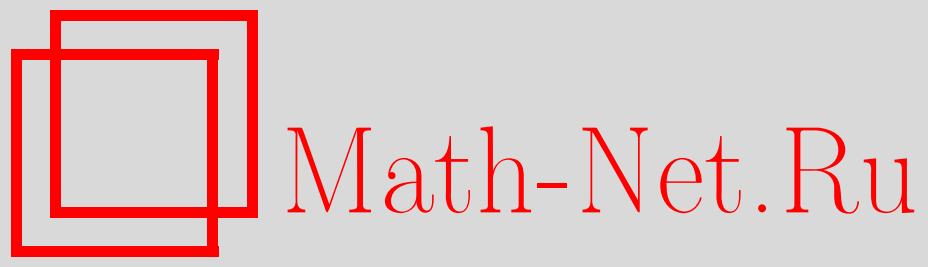

A. Baltrūnas, E. Omey, Second order renewal theorem in the finite-means case, Теория вероятн. и ее примен., 2002, том 47, выпуск 1, 178-182

DOI: https://doi.org/10.4213/tvp3381

Использование Общероссийского математического портала MathNet.Ru подразумевает, что вы прочитали и согласны с пользовательским соглашением

http://www . mathnet.ru/rus/agreement

Параметры загрузки:

IP : 54.224 .60 .19

26 апреля 2023 г., 15:59:42

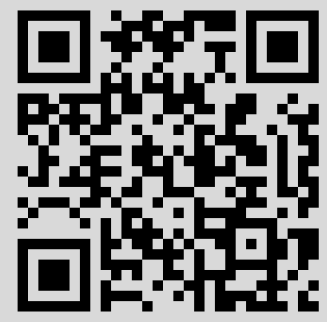


5. Ибрагимов И.А. О точности аппроксимации функций распределения сумм независимых величин нормальным распределением. - Теория вероятн. и ее примен., 1966, т. 11, в. 4 , с. $632-655$.

6. Розовский Л. В. О точности нормального приближения. - Зап. науч. семин. ЛОМИ, 1989 , т. 177 , с. $129-137$.

7. Rozovsky L.V. On approximation accuracy for distribution functions of the sum of independent random variables using infinitely divisible distributions. - Proceedings of the Forth International Vilnius Conference on Probability Theory and Mathematical Statistics, 1985. V. II. Ed. by Yu. Prokhorov et al., Utrecht: VNU Sci. Press, 1987, p. 501-507.

8. Розовский Л. В. О точности приближения функции распределения суммы независимых случайных величин. - Теория вероятн. и матем. статист., 1991, т. 45, c. 97-104.

9. Петров В.В. Суммы независимых случайных величин. М.: Наука, 1972, 416 с.

10. Maesono $Y$. Lower bounds for the normal approximation of a sum of independent random variables. - Austral. J. Statist., 1989, v. 31, № 3, p. 475-485.

11. Сунклодас И. Об оценке снизу скорости сходимости в центральной предельной теореме для $m$-зависимых полей. - Теория вероятн. и ее примен., 1998, т. 43, № 1 , c. 171-179.

12. Розовский Л. В. О точности приближения характеристической функции полиномами. - Зап. науч. семин. ЛОМИ, 1985, т. 142, с. 141-144.

13. Розовский Л. В. О коэффициентах ряда Крамера. - Теория вероятн. и ее примен., 1998 , т. 43 , № 1 , с. $161-166$.

Поступила в редакцию 26.X.1999

(C) $2001 \mathrm{\Gamma}$.

\section{BALTR $\bar{U} N A S$ A. ${ }^{*}$, OMEY E.**}

\section{SECOND ORDER RENEWAL THEOREM IN THE FINITE-MEANS CASE}

Пусть $F-$ функция распределения на $(0, \infty)$ и $U-$ связанная с ней функция восстановления. Хорошо известно, что если $F$ имеет конечный первый момент $\mu$, то $U(t)$ асимптотически равна $t / \mu$. Также хорошо известно, что $U(t)-t / \mu$ асимптотически ведет себя как $S(t) / \mu$, где $S$ обозначает повторный интеграл от хвоста распределения $F$. В настоящей статье обсуждается скорость сходимости $U(t)-t / \mu-S(t) / \mu$ для широкого класса функций распределения. Наши оценки улучшают результаты [7], [12], [4].

Ключевые слова и фразы: функция восстановления, субэкспоненщиальные распределения, правильно меняющаяся функция.

1. Introduction. Let $X_{1}, X_{2}, \ldots$ be i.i.d. positive random variables with common distribution function (d.f.) $F$. We assume, throughout this paper, that $F$ is nonsingular. Let $S_{0}=0$, and for $n \geqslant 0$, let $S_{n+1}=S_{n}+X_{n+1}$. Central object in renewal theory is the counting process $N(t), t \geqslant 0$, defined by the first passage times for the random walk $S_{n}$, $n \geqslant 0$, i.e.,

$$
N(t)=n \quad \text { if and only if } S_{n-1} \leqslant t<S_{n} .
$$

The expected value $U(t)=\mathbf{E} N(t), t \geqslant 0$, is the so-called renewal function. It is well known that $U(t)=\sum_{n=0}^{\infty} \mathbf{P}\left\{S_{n} \leqslant t\right\}, t \geqslant 0$.

* Institute of Mathematics and Informatics, Akademijos 4, 2600 Vilnius, Lithuania; e-mail: baltrunas@takas.lt

** EHSAL, Stormstraat 2, 1000 Brussels, Belgium; e-mail: omedward@prof.ehsal.be 
Many authors have investigated the asymptotic behaviour of $U(t)$ as $t \rightarrow \infty$. If $X_{1}$ has finite mean $\mu=\mathbf{E} X_{1}$, it is well known (cf. [5]) that $U(t)-t / \mu$ is nonnegative and that

$$
U(t) t^{-1} \rightarrow \mu^{-1}, \quad \text { as } t \rightarrow \infty .
$$

Moreover, if $F$ is not arithmetic, Blackwell's theorem states that

$$
U(t+y)-U(t) \rightarrow y \mu^{-1}, \quad \text { as } t \rightarrow \infty .
$$

Second-order results can be proved by using Stieltjes convolutions of the form

$$
Q * U(t)=\int_{0-}^{t} Q(t-u) d U(u), \quad t \geqslant 0
$$

where $Q$ is a nonnegative function.

As important examples we mention here two results.

For convenience, we define $R(t):=\int_{0}^{t} Q(u) d u, t \geqslant 0$.

Proposition 1.1 ([5]). If $Q$ is directly Riemann integrable and if $F$ is not arithmetic, then $Q * U(t) \rightarrow R(\infty) / \mu$, as $t \rightarrow \infty$.

Proposition 1.2 (Theorem 4 of [11]; [6]). Suppose $F$ is not arithmetic and has finite first moment $\mu$ and suppose that $Q$ is nonincreasing. Then $Q * U(t) / R(t) \rightarrow 1 / \mu$, as $t \rightarrow \infty$.

The previous results can be used to obtain the precise asymptotic behaviour of $U(t)-t / \mu$ as follows.

Let us define the integrated tail distribution $F_{1}$ of $F$, i.e.,

$$
F_{1}(t)=\mu^{-1} \int_{0}^{t} \bar{F}(u) d u, \quad t \geqslant 0,
$$

where $\bar{F}:=1-F$.

Denote

$$
S(t)=\int_{0}^{t} \bar{F}_{1}(u) d u, \quad t \geqslant 0 .
$$

It is easy to see that $F_{1} * U(t)=t / \mu$. Choosing $Q=\bar{F}_{1}$ in Propositions 1.1 and 1.2 , we have $R(t)=S(t)$ and we obtain the following rate of convergence result for (1.1).

Proposition 1.3. Assume that $F$ is not arithmetic.

(i) If $S(t) \rightarrow \infty$, then $U(t)-t / \mu \sim S(t) / \mu$.

(ii) If $\mu_{2}=\mathbf{E} X_{1}^{2}<\infty$, then $U(t)-t / \mu \rightarrow \mu_{2} /\left(2 \mu^{2}\right)$.

The present paper is devoted to the asymptotic behaviour of the difference $Q * U(t)-$ $R(t) / \mu$ for a large class of functions $Q$. The estimate improves earlier results of Geluk [7], Teugels [12] and Embrechts and Omey [4].

2. Main result. In what follows we study the rate of convergence in Proposition 1.2. Denote

$$
Z(t)=U(t)-t \mu^{-1} ; \quad R(t)=\int_{0}^{t} Q(u) d u ; \quad V(t)=Q * U(t)-R(t) \mu^{-1}, \quad t \geqslant 0 .
$$

For any two nonnegative and measurable functions $h$ and $g$ define their Lebesgue convolution $h \star g$ by $h \star g(t)=\int_{0}^{t} h(t-u) g(u) d u, t \geqslant 0$. About the function $Q$ we shall make the following assumption: $Q$ has the form

$$
Q(t):=\int_{t}^{\infty} q(u) d u
$$

where $q(u) \geqslant 0, u \geqslant 0$.

The class $\mathscr{D} \mathscr{L}$ consists of those nonnegative and measurable functions $g$ for which for all real $y$

$$
0<\liminf _{x \rightarrow \infty} \frac{g(x+y)}{g(x)} \leqslant \limsup _{x \rightarrow \infty} \frac{g(x+y)}{g(x)}<\infty .
$$

The following relation is easy to prove.

Lemma 2.1. $V(t)=Z(t) Q(t)+\int_{0}^{t}(Z(t)-Z(t-y)) q(y) d y$. 
Clearly we have to estimate $Z(t)-Z(t-y)$. To this end we shall use the class of subexponential d.f.'s and related classes of functions.

We say that $F$ belongs to the subexponential class $\mathbf{S}$ if $\mathbf{P}\left\{S_{n}>t\right\} / \mathbf{P}\left\{X_{1}>t\right\} \rightarrow n$ as $t \rightarrow \infty$, for $n=2$ (and consequently for all $n \geqslant 2$ ).

Note that if $F \in \mathbf{S}$, then automatically $\bar{F} \in \mathscr{L}$, where $\mathscr{L}$ denotes the class of nonnegative and measurable functions $g$ such that $\lim _{x \rightarrow \infty} g(x+y) / g(x)=1$, for all real $y$. References for $\mathbf{S}$ and its basic properties can be found, e.g., in [13], [10] or [3]. Using subexponential distributions, Ney [8] proved the following nice refinement of Blackwell's theorem.

Lemma $2.2([8])$. Assume that $F$ is nonsingular distribution function. If $F_{1} \in \mathbf{S}$, then for all real $y$,

$$
|Z(t+y)-Z(t)|=O(1) \bar{F}_{1}(t) .
$$

From [9, Proposition 2.1] it follows that (2.2) automatically holds locally uniformly in $y$.

Our main result is the following.

Theorem 2.1. Assume that $F$ is a nonsingular distribution function and assume that $Q$ satisfies (2.1). If $F_{1} \in \mathbf{S}$ and $Q \in \mathscr{D} \mathscr{L}$, then

$$
V(t)=O(1)\left(Q(t) S(t)+\bar{F}_{1} \star Q(t)+\bar{F}_{1}(t)\right) .
$$

$\mathrm{P}$ r o o f. From Lemma 2.2 we see that there exist positive numbers $K$ and $N$ such that

$$
|Z(t-y)-Z(t-y-u)| \leqslant K \bar{F}_{1}(t-y)
$$

for all $t$ and $y$ such that $t-y \geqslant N$, uniformly in $0 \leqslant u \leqslant 1$.

Now we consider the integral in Lemma 2.1 and we split the integral into two terms $A+B$, where

$$
\begin{aligned}
& A:=\int_{0}^{t-N}(Z(t)-Z(t-y)) q(y) d y, \\
& B:=\int_{t-N}^{t}(Z(t)-Z(t-y)) q(y) d y .
\end{aligned}
$$

First consider $B$. By setting $M=\sup _{0 \leqslant y \leqslant N} Z(y)$, we obtain $|B| \leqslant(Z(t)+M)(Q(t-$ $N)-Q(t)$ ). Since $Q \in \mathscr{D} \mathscr{L}$, it follows that $B=O(1) Z(t) Q(t)$.

Next we consider $A$. Using $[y]$, the integer part of $y$, we have

$$
\begin{aligned}
Z(t)-Z(t-y) & =Z(t)-Z(t-[y])+Z(t-[y])-Z(t-y) \\
& =\sum_{r=0}^{[y]-1}(Z(t-r)-Z(t-r-1))+Z(t-[y])-Z(t-y) .
\end{aligned}
$$

Using (2.3) this yields

$$
Z(t)-Z(t-y) \leqslant K \sum_{r=0}^{[y]-1} \bar{F}_{1}(t-r)+K \bar{F}_{1}(t-y) \leqslant K \int_{t-y}^{t} \bar{F}_{1}(u) d u+K \bar{F}_{1}(t-y) .
$$

The integral $A$ we can split into two parts such that $|A| \leqslant A(1)+A(2)$, where

$$
\begin{aligned}
& A(1)=K \int_{0}^{t} \int_{t-y}^{t} \bar{F}_{1}(u) d u q(y) d y, \\
& A(2)=K \int_{0}^{t-N} \bar{F}_{1}(t-y) q(y) d y .
\end{aligned}
$$

First consider $A(1)$. Using partial integration we have

$$
\begin{aligned}
A(1) & =-K \int_{0}^{t} \int_{t-y}^{t} \bar{F}_{1}(u) d u d Q(y) \\
& =-K Q(t) \int_{0}^{t} \bar{F}_{1}(u) d u+K \int_{0}^{t} Q(y) \bar{F}_{1}(t-y) d y \\
& =O(1)\left(Q(t) S(t)+\bar{F}_{1} \star Q(t)\right) .
\end{aligned}
$$


Similarly, we obtain that

$$
\begin{aligned}
A(2) & =-K \int_{0}^{t-N} \bar{F}_{1}(t-y) d Q(y) \\
& =-K Q(t-N) \bar{F}_{1}(N)+K Q(0) \bar{F}_{1}(t)+K \int_{0}^{t-N} Q(y) \bar{F}(t-y) d y / \mu .
\end{aligned}
$$

Since $F_{1} \in \mathbf{S}$, we have $\bar{F}_{1} \in \mathscr{L}$ and hence $\bar{F}(t) / \bar{F}_{1}(t) \rightarrow 0$ as $t \rightarrow \infty$. From this it follows that $\int_{0}^{t-N} Q(y) \bar{F}(t-y) d y=o(1) \bar{F}_{1} \star Q(t)$ as $t \rightarrow \infty$.

Summarizing we obtain $A=O(1)\left(Q(t) S(t)+\bar{F}_{1} \star Q(t)+\bar{F}_{1}(t)\right)$. Now combine this estimate with the estimate for $B$. It readily follows that

$$
V(t)=O(1)\left(Q(t) S(t)+\bar{F}_{1} \star Q(t)+\bar{F}_{1}(t)\right) .
$$

This completes the proof of Theorem 2.1.

$\mathrm{R}$ e $\mathrm{m}$ a $\mathrm{r}$ k. Our main Theorem 2.1 generalizes a result of Geluk [7] and Teugels [12], where it is assumed that $F$ is in the domain of attraction of a stable law and where the functions involved are assumed to be regularly varying.

3. Corollaries. From Proposition 1.3 and Theorem 2.1 we have the following corollaries.

In the special case where $Q=\bar{F}_{1}$, the following refinement of Proposition 1.3 holds.

Corollary 3.1. Suppose the conditions of Theorem 2.1 hold.

(i) Then

$$
Z(t)-S(t) \mu^{-1}=O(1)\left(\bar{F}_{1}(t) S(t)+\bar{F}_{1} \star \bar{F}_{1}(t)\right) .
$$

(ii) If also $\mu_{2}=\mathbf{E} X_{1}^{2}<\infty$, then

$$
Z(t)-S(t) \mu^{-1}=O(1)\left(\bar{F}_{1}(t)+\bar{F}_{1} \star \bar{F}_{1}(t)\right) .
$$

The formulas above show that we should study expressions of the form $a \star b(t)$ and $a \star a(t)$, where the functions $a$ and $b$ are nonnegative. In [1], the authors studied several classes of functions related to the class $\mathbf{S}$. In our paper [1] we defined the classes $O A$ and $B B$ as follows. The function $a \in O A$ if and only if $a \star a(t)=O(1) a(t) A(t)$, where $A(t)$ is the integral of $a$ in the region $[0, t]$. The function $a \in B B$ if and only if $\lim _{t \rightarrow \infty} a \star$ $a(t) /(a(t) A(t))$ exists. If $a$ is a density function, then the class $B B$ corresponds to the so-called class of subexponential densities.

The next corollary is the main result of [2].

Corollary 3.2. Suppose that the conditions of Theorem 2.1 hold.

(i) If $\bar{F}_{1} \in O A$, then

$$
Z(t)-S(t) \mu^{-1}=O(1) \bar{F}_{1}(t) S(t) .
$$

(ii) If also $\mu_{1}=\mathbf{E} X_{1}^{2}<\infty$, then

$$
Z(t)-S(t) \mu^{-1}=O(1) \bar{F}_{1}(t)
$$

The class $O A$ contains so-called functions of dominated variation, cf. Lemma 3.1(ii) below. We say that the positive and measurable function $g$ belongs to the class $O R V$ if

for all $y>0$.

$$
\limsup _{t \rightarrow \infty} \frac{g(t y)}{g(t)}<\infty
$$

From well-known properties of $O R V$, it follows that (3.1) holds locally uniformly in $y$. Moreover, (3.1) implies that $\liminf _{t \rightarrow \infty} g(t y) / g(t)>0$, for all $y>0$ and that $g \in \mathscr{D} \mathscr{L}$. The class $O R V$ contains the class of regularly varying functions. It is also well known that if $\bar{F} \in O R V \cap \mathscr{L}$, then $F \in \mathbf{S}$. For a survey of results and applications, we refer to [3], [5].

Lemma 3.1. Suppose $a(t) \geqslant 0$ and $b(t) \geqslant 0$ and let $A(t)$ (resp. $B(t)$ ) denote the integral of $a(\cdot)$ (resp. $b(\cdot))$ in the region $[0, t]$.

(i) If $a \in O R V$ and $b \in O R V$, then $a \star b(t)=O(1)(a(t) B(t)+b(t) A(t))$.

(ii) If $a \in O R V$, then $a \star a(t)=O(1) a(t) A(t)$, i.e., $a \in O A$. 
P r o o f. We have $a \star b(t)=\int_{0}^{t / 2} a(t-y) b(y) d y+\int_{0}^{t / 2} b(t-y) a(y) d y$. Since $a \in O R V$ and $b \in O R V$, it follows that for $0 \leqslant y \leqslant t / 2, a(t-y) / a(t)=O(1)$ and $b(t-y) / b(t)=O(1)$ uniformly in $y$.

The result follows.

Combining Lemma 3.1 with the previous obtained results, we have the following interesting Corollary.

Corollary 3.3. Suppose the conditions of Theorem 2.1 hold.

(i) If $Q \in O R V$ and $\bar{F}_{1} \in O R V$, then $V(t)=O(1)\left(Q(t) S(t)+\bar{F}_{1}(t) R(t)\right)$.

(ii) If $Q=\bar{F}_{1} \in O R V$, then $Z(t)-S(t) \mu^{-1}=O(1) \bar{F}_{1}(t) S(t)$.

(iii) If $Q=\bar{F}_{1} \in O R V$ and $\mu_{2}=\mathbf{E} X_{1}^{2}<\infty$, then $Z(t)-S(t) \mu^{-1}=O(1) \bar{F}_{1}(t)$.

P r o o f. (i) From Theorem 2.1 we have $V(t)=O(1)\left(Q(t) S(t)+\bar{F}_{1}(t)+\bar{F}_{1} \star\right.$ $Q(t))$. Using Lemma 3.1 , we have $\bar{F}_{1} \star Q(t)=O(1)\left(Q(t) S(t)+\bar{F}_{1}(t) R(t)\right)$. Since $R(t)$ is nondecreasing, the result follows.

(ii) This follows from (i).

(iii) This is a special case of (ii).

R e m a r k. Part (iii) of Corollary 3.3 generalizes a result of Embrechts and Omey [4], where they obtained an estimate of the form $Z(t)-S(t) / \mu=o(1) t \bar{F}_{1}(t)$.

Acknowledgments. This paper was finished during a visit of the first author to EHSAL-Brussels in the framework of the Exchange Programme between the Flemish Community and the Republic Lithuania. I would like to thank EHSAL for its kind hospitality, and the Flemish Community and the Republic Lithuania for financial support.

\section{REFERENCES}

1. Baltrūnas A., Omey E. The rate of convergence for subexponential distributions. Liet. Mat. Rink., 1998, v. 38, № 1, p. 1-18.

2. Baltrūnas A. Simple proof of the second order renewal theorem. - Proc. Lith. Math. Soc., 1998 , v. 2, p. 489-491.

3. Bingham N. H., Goldie C.M., Teugels J. L. Regular Variation. Cambridge: Cambridge Univ. Press, 1987, $491 \mathrm{p}$.

4. Embrechts P., Omey E. A property of longtailed distributions. - J. Appl. Probab., 1984 , v. 21 , p. $80-87$.

5. Феллер В. Введение в теорию вероятностей и ее приложения. Т. 2. М.: Мир, 1984, $752 \mathrm{c}$.

6. Frenk J. B. G. On Banach Algebras, Renewal Measures and Regenerative Processes. Amsterdam: Stichting Mathematisch Centrum, 1987, 201 p. (CWI Tract, v. 38).

7. Geluk J. L. A renewal theorem in the finite-mean case. - Proc. Amer. Math. Soc., 1997 , v. 125 , № 11 , p. 3407-3413.

8. Ney P. A refinement of the coupling method in renewal theory. - Stochastic Process. Appl., 1981, v. 11, p. 11-26.

9. Omey E. On a subclass of regularly varying functions. - J. Statist. Plann. Inference, 1995 , v. 45, № 1-2, p. 275-290.

10. Pitman E.J.G. Subexponential distribution functions. - J. Austral. Math. Soc. Ser. A, 1980 , v. 29 , p. $337-347$.

11. Сгибнев М. С. О теореме восстановления в случае бесконечной дисперсии. - Сиб. матем. журн., 1981, т. 22, № 5, с. 178-189.

12. Teugels J.L. Renewal theorems when the first or the second moment is infinite. Ann. Math. Statist., 1968, v. 39, p. 1210-1219.

13. Teugels J. L. The class of subexponential distributions. - Ann. Probab., 1975, v. 3, p. 1000-1011. 